\title{
Differential effects of immediate posttraining sulpiride microinfusions into the nucleus accumbens shell and core on Morris water maze retention
}

\author{
BARRY SETLOW and JAMES L. MCGAUGH \\ University of Califormia, Irvine, Califormia
}

\begin{abstract}
Extensive evidence indicates that the nucleus accumbens is involved in spatial learning and memory tasks. There has been relatively little inquiry, however, into which of the two anatomically and functionally distinct subregions of the nucleus accumbens (the shell and the core) mediate this involvement. To investigate this issue, male Sprague-Dawley rats implanted with bilateral intracerebral guide cannulae aimed at the medial shell or core were given eight training trials in the standard hidden platform version of the Morris water maze, immediately followed by intracerebral microinfusions of the D2 dopamine antagonist sulpiride or saline vehicle. A probe trial retention test 2 days later revealed that sulpiride microinfusions into the shell significantly increased latency to reach the platform location, whereas sulpiride microinfusions into the core significantly decreased the time spent swimming near the platform location and significantly increased the time spent swimming in the maze periphery. The results suggest that the nucleus accumbens shell and core may be involved in the consolidation of memory for different aspects of water maze task performance.
\end{abstract}

As the publication of this issue of Psychobiology demonstrates, there exists a growing appreciation of the role of the nucleus accumbens (NA) in numerous cognitive processes, including learning and memory. Investigation of the mnemonic role of the NA was begun (to our knowledge) by Lorens, Sorenson, and Harvey (1970) and has expanded rapidly in the past several years. The more recent work consists largely of findings that, in both rodents and primates, lesions and drug microinfusions in the NA affect performance in a variety of learning and memory tasks, including the spatial version of the Morris water maze, radial arm maze, spatial discrimination, and avoidance tasks, and several appetitive and aversive classical conditioning tasks (Everitt, Morris, O'Brien, \& Robbins, 1991; Gal, Joel, Gusak, Feldon, \& Weiner, 1997; Lorenzini, Baldi, Bucharelli, \& Tassoni, 1995; McCullough, Sokolowski, \& Salamone, 1993; Parkinson, Willoughby, Robbins, \& Everitt, 1997; Ploeger, Spruijt, \& Cools, 1994; Seamans \& Phillips, 1994; Stern \& Passingham, 1995; Sutherland \& Rodriguez, 1989; Taghzouti, Garrigues, Labouesse, Le Moal, \& Simon, 1987; Westbrook, Good, \& Kiernan, 1997; for a partial review, see Setlow, 1997). The

This material is based on work supported by a National Science Foundation Graduate Fellowship (to B.S.) and NIMH Research Grant MH12526 (to J.L.M.). We thank My T. Kha, Christian A. Pham, and Michelle B. Uaje for their invaluable technical assistance and Nancy Collett for editorial assistance. Correspondence concerning this article should be addressed to B. Setlow, Department of Psychology, Johns Hopkins University, 224 Ames Hall, 3400 North Charles St., Baltimore, MD 21218 (e-mail: bsetlow@ren.psy.jhu.edu). effects of NA manipulations cannot easily be attributed to perceptual, motor, or motivational changes, because it has been demonstrated in several studies that the same NA manipulations that affect performance in the tasks listed above have no effects in other, related tasks with similar performance demands (e.g., the cued version of the Morris water maze or a visual discrimination task; Seamans \& Phillips, 1994; Stern \& Passingham, 1995; Sutherland \& Rodriguez, 1989; Westbrook et al., 1997).

In addition to controlling for the effects of NA manipulations on nonmnemonic components of task performance, these dissociations suggest that the NA is involved only in specific forms of learning and memory and not in others, as has been demonstrated for other brain regions, such as the hippocampal formation (Packard, Cahill, \& McGaugh, 1994; Squire \& Knowlton, 1994). This suggestion is consistent with evidence concerning the sources of cortical inputs to the NA (such as the hippocampal formation, the basolateral complex of the amygdala, and the cingulate cortex), which mediate learning and memory in the tasks listed above and in which manipulations produce many of the same effects that are found with NA manipulations (Everitt et al., 1991; McGeorge \& Faull, 1989; Packard \& White, 1991; Parkinson et al., 1997; Seamans \& Phillips, 1994; Sutherland \& Rodriguez, 1989). This relationship has been made explicit in several studies reporting that asymmetric contralateral lesions of the NA and one of its cortical afferents produce the same patterns of effects on learning and memory as do bilateral NA or cortical afferent lesions (Everitt et al., 1991; Floresco, Seamans, \& Phillips, 1997; Parkinson et al., 1997). 
Recent work from our laboratory provides additional evidence for a mnemonic role of the NA. Microinfusions of the D2 dopamine receptor antagonist sulpiride into the NA immediately following training impaired retention 2 days later (as assessed by latency to reach the platform location) in the spatial but not in the cued version of the Morris water maze (Setlow \& McGaugh, 1998). These results not only reinforce the idea that the NA is involved in forms of learning and memory related to those associated with its cortical afferents (in this case, presumably the hippocampal formation), but also, through the use of a posttraining, temporary manipulation, provide evidence that the NA is involved in consolidation of this form of memory.

In the majority of the experiments described above, the lesions or drug microinfusions in the NA affected the entire structure. The NA consists of two distinct subregions, however, termed the core and shell, which differ in their neurochemistry and patterns of connections with other brain regions (Heimer, Zahm, \& Alheid, 1995). These two subregions also differ in their involvement in several aspects of behavior, including performance in learning and memory tasks (Carlezon \& Wise, 1996; Maldonado-Irizarry \& Kelley, 1995b; Sokolowski \& Salamone, 1998; Weiner, Gal, Rawlins, \& Feldon, 1996). For example, in rats, intracore microinfusions of glutamate receptor antagonists were more disruptive to performance in a spatial food-search task than were intrashell microinfusions (Maldonado-Irizarry \& Kelley, 1995a).

In our previous paper (Setlow \& McGaugh, 1998), we suggested that the effects of sulpiride on water maze retention might be due primarily to disruption of memory consolidation processes in the core. This speculation was based on the work of Maldonado-Irizarry and Kelley (1995a), described above, as well as on the fact that our microinfusions were centered within this subregion. The present experiment sought to address this issue explicitly, through the use of sulpiride microinfusions administered into the core or shell immediately after training in the spatial version of the Morris water maze. An additional goal of these experiments was to explore the involvement of the shell and core in memory for different aspects of the water maze task. Successful water maze performance requires memory not only for the spatial location of the hidden platform, but also for nonspatial, or "procedural", components of the task, such as swimming away from the walls of the maze (Devan, Goad, \& Petri, 1996). These components, of which there are probably several, seem to be anatomically and pharmacologically dissociable from memory for the platform location (Bannerman, Good, Butcher, Ramsay, \& Morris, 1995; Devan et al., 1996). Accordingly, several measures of retention were used, in an attempt to assess the involvement of the shell and core in consolidation of memory for different task components.

\section{METHOD}

The methods have been described previously (Setlow \& McGaugh, 1998).

\section{Animals}

The subjects were 93 male Sprague-Dawley rats (Charles River, San Diego) weighing 225-250 g upon arrival. They were individually housed in a temperature-controlled colony room $\left(22^{\circ} \mathrm{C}\right)$ and maintained on a 12:12-h light:dark cycle (6 a.m.-6 p.m., lights on) with ad-lib access to food and water.

\section{Surgery}

Approximately 1 week after their arrival, the rats were anesthetized with sodium pentobarbital $(65 \mathrm{mg} / \mathrm{kg}$ i.p. Nembutal, Abbott Laboratories, Chicago), which was supplemented with methoxyflurane (Metofane) as needed, and were given atropine sulfate $(0.05 \mathrm{mg}$, i.p.) to maintain respiration. Their skulls were fixed to a stereotaxic frame (Kopf Instruments, Tujunga, CA), a midline incision was made, and holes were drilled in the skull for cannulae and three anchoring screws. Guide cannulae ( 23 ga., $15 \mathrm{~mm}$ ) were implanted bilaterally above the NA shell or core (flat skull coordinates from bregma-shell: AP, $+1.7 \mathrm{~mm}$; ML, $\pm 0.9 \mathrm{~mm}$; DV, $-5.2 \mathrm{~mm}$ from skull; core: AP, $+1.7 \mathrm{~mm}$; ML, $\pm 1.9 \mathrm{~mm}$; DV, $-5.2 \mathrm{~mm}$ from skull). The guide cannulae were affixed to the skull and the anchoring screws with dental cement, and the incision was closed with wound clips. Immediately after surgery, the rats received injections of penicillin $(0.05 \mathrm{ml}, \mathrm{i} . \mathrm{m}$.) and physiological saline $(3 \mathrm{ml}, \mathrm{s.c}$.$) and$ were placed in a temperature-controlled incubator until they recovered from anesthesia. Stylets ( $15 \mathrm{~mm}, 00$ insect pins) were inserted into the guide cannulae to maintain patency.

\section{Apparatus}

The water maze was a circular black-painted metal tank $(1.83 \mathrm{~m}$ in diameter, $0.58 \mathrm{~m}$ in height), the floor of which was raised $60 \mathrm{~cm}$ above the room floor. It was located in a room $(3 \times 3.6 \mathrm{~m})$ containing several extra-maze cues (including the door, cabinets, and several posters on the walls) and was filled with water $\left(25^{\circ} \pm 1^{\circ} \mathrm{C}\right)$ to a depth of $22 \mathrm{~cm}$. Four start positions (labeled N, S, E, and W) were located equidistantly around the edge of the maze, dividing it into four equal quadrants. During training, a transparent Plexiglas platform $(25 \times 20 \times 19.5 \mathrm{~cm})$ was submerged $2.5 \mathrm{~cm}$ below the surface of the water in the NE quadrant of the maze.

\section{Drug Microinfusions}

(-)-Sulpiride (Sigma, St. Louis, MO) was dissolved in $0.9 \%$ saline. Although sulpiride is usually dissolved in slightly acidic solutions, we found that, at the low concentrations used here, it went into solution with extensive stirring. Saline alone was used for control microinfusions. All microinfusions were administered in a volume of $0.3 \mu \mathrm{l} /$ side through bilateral needles ( $30 \mathrm{ga} ., 17 \mathrm{~mm}$ ) placed in the guide cannulae. The needles were attached by lengths of plastic tubing (PE 20) to 10- $\mu$ l syringes (Hamilton, Reno, NV), which were mounted on a timer-controlled infusion pump (Sage Instruments, Boston). Microinfusions took place over $35 \mathrm{sec}$, after which the needles were left in place for $60 \mathrm{sec}$ to allow for diffusion.

\section{Behavioral Procedures}

The rats were allowed to recover for at least 1 week following surgery, during which they were handled three times for $1 \mathrm{~min}$ each. All the procedures were carried out between 10 a.m. and 3 p.m. Training consisted of a single session of eight trials, with the start positions in a pseudorandom order so that each of the four start positions was used twice. On each training trial, the rats were placed into the water, facing the wall of the maze at one of the start posi- 
A

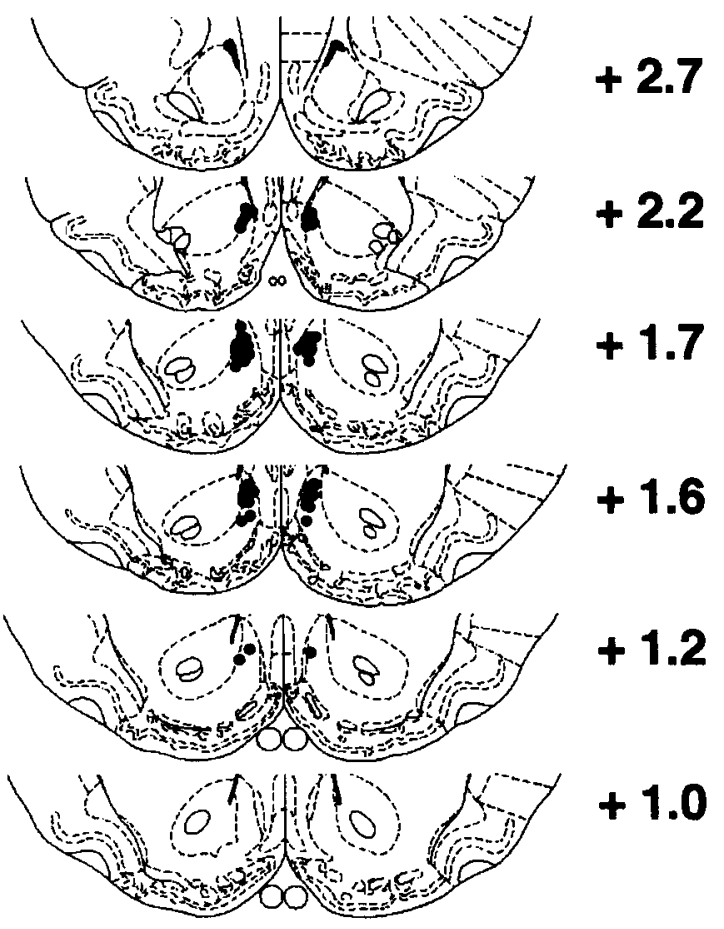

B

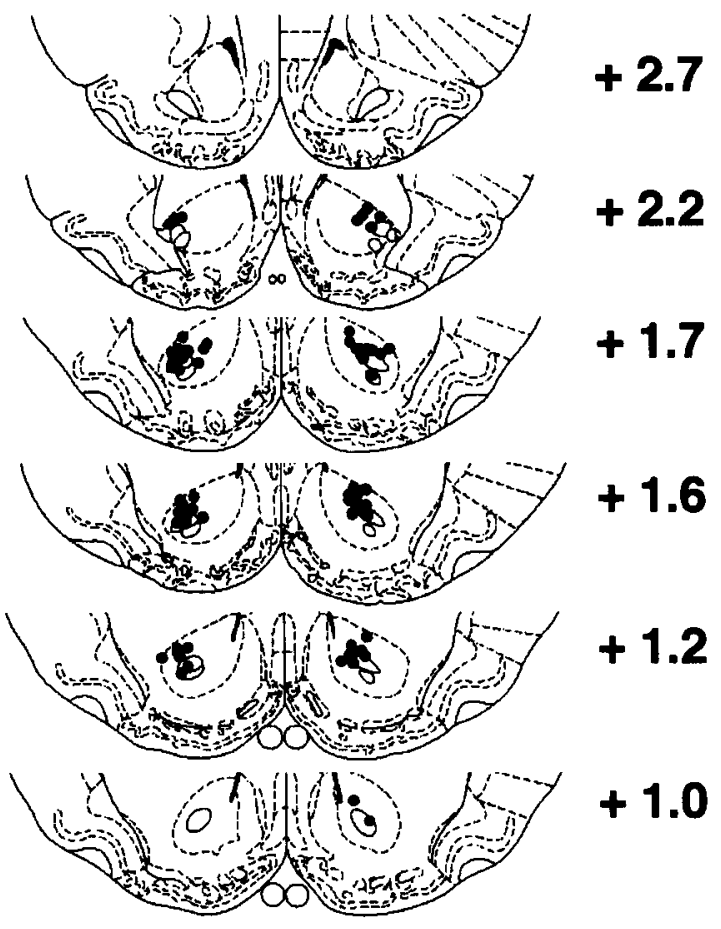

Figure 1. Microinfusion needle tip locations in the nucleus accumbens. A: locations in shell animals. B: locations in core animals. Plates adapted from The Rat Brain in Stereotaxic Coordinates (Figures 9-14), by G. Paxinos and C. Watson, 1997, San Diego: Academic Press. Copyright 1997 by Academic Press. Adapted with permission.

tions, and their latencies to swim to the platform were recorded. Rats that failed to find the platform within $60 \mathrm{sec}$ were guided to it by hand. After reaching the platform, the rats were allowed to remain on it for $20 \mathrm{sec}$; they were then removed to a holding cage for a $30-\sec$ intertrial interval.

Drug microinfusions were initiated immediately after the last training trial. The stylets were removed from the cannulae, and microinfusions (saline, 10- or 100-ng/side sulpiride) were given. The stylets were then replaced, and the rats were returned to their home cages.

Two days later, the rats were returned to the water maze for a retention test. The test consisted of a $90-\mathrm{sec}$ probe trial in which the platform was removed and a start position midway between the $S$ and the E start positions was used. A camera mounted above the maze was used to videotape the test sessions. Latency to reach the platform location in the NE quadrant of the maze, time spent swimming within a $57-\mathrm{cm}$-diameter annulus surrounding the platform location (annulus time), and time spent swimming within $10 \mathrm{~cm}$ of the maze wall (periphery time) were recorded from the videotapes, using a stopwatch. Path length to the platform location was recorded from the videotapes by tracing the rats' swim paths on the video screen, using a hand-held map measurer. All training, testing, and retention data collection was done blind to drug treatment condition.

\section{Histology}

After testing, the rats were given an overdose of pentobarbital and perfused intracardially with $0.9 \%$ saline followed by $4 \%$ formaldehyde, and their brains were removed and stored in $4 \%$ formaldehyde. The brains were then sliced on a freezing microtome, and coronal sections $(80 \mu \mathrm{m})$ were collected through the area of the NA. Sections were mounted on glass slides, stained with thionin, and coverslipped with Permount. Placements of the microinfusion needles were verified under a light microscope by an observer blind to drug treatment condition and were mapped onto plates adapted from the atlas of Paxinos and Watson (1997).

\section{Statistics}

Training latencies were analyzed using repeated measures analyses of variance (ANOVAs), with training trial as the within-subjects variable and drug treatment as the between-subjects variable. Retention data were analyzed using one-factor ANOVAs, with drug treatment as the between-subjects variable. Post hoc comparisons between groups were done with Fisher's PLSD. In all cases, $p$ values less than .05 were considered significant. Outliers, defined as scores outside the range of $\pm 2 S D$ from the group mean, were excluded from each group prior to statistical analysis. The following scores were excluded on these grounds. Platform location latency: shell, one each in the saline and 10-ng sulpiride groups; core, one in each group. Annulus time: shell, one each in the 10- and 100-ng sulpiride groups; core, one in the 10-ng sulpiride group. Periphery time: core, one in the 100-ng sulpiride group. Path length: shell, one each in the saline and 10-ng sulpiride groups; core, one each in the saline and 10-ng sulpiride groups.

\section{RESULTS}

\section{Histology}

Microinfusion needle placements for the shell and core animals are shown in Figure 1. Eighteen animals ( 9 shell 

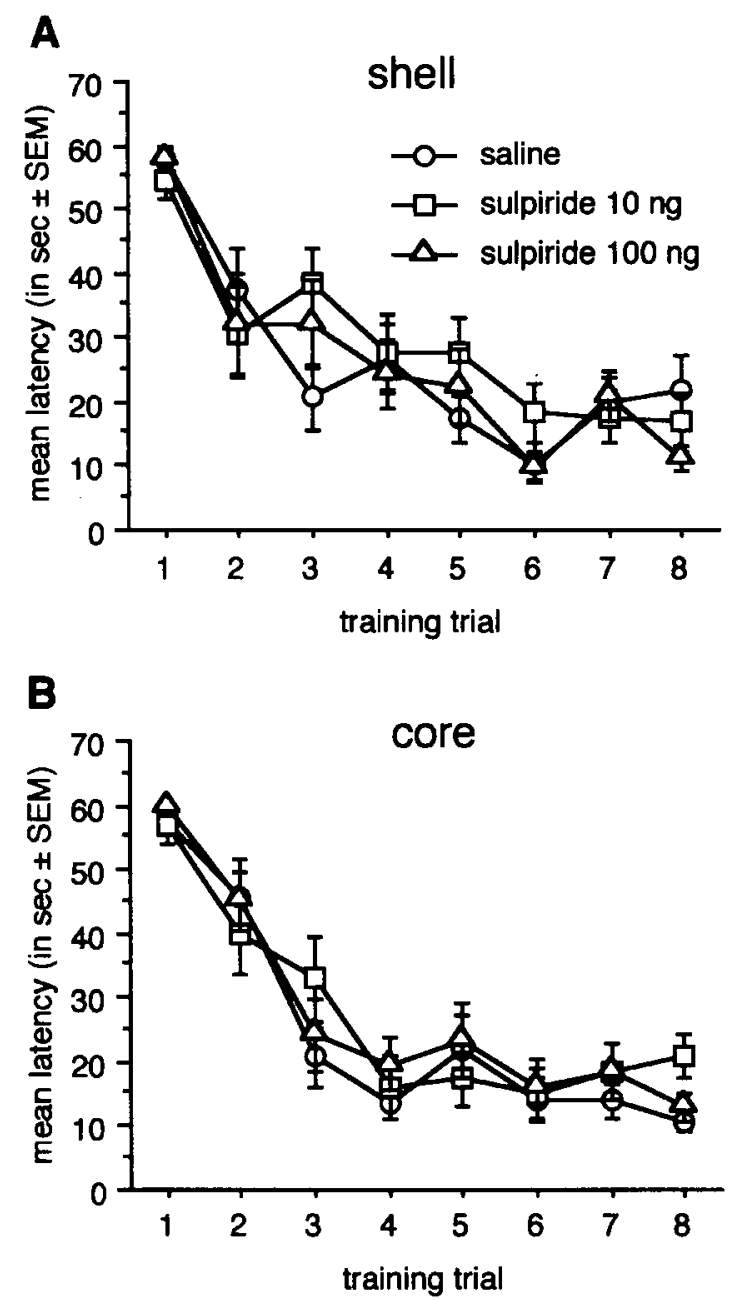

Figure 2. Mean ( $\pm S E M$ ) latencies to reach the platform during training in (A) shell and (B) core animals.

and 9 core) were excluded from further analysis, either because their placements were outside the appropriate region or because of bleeding at the microinfusion site.

\section{Behavior}

Acquisition. Repeated measures ANOVAs revealed a significant effect of training trial in both the shell $[F(7,238)=25.02, p<.0001]$ and the core $[F(7,245)=$ $45.06, p<.0001]$ animals. There were no significant between-group differences, however, in either the shell $[F(2,34)=0.51, p>.05]$ or the core $[F(2,35)=0.63, p>$ .05 ] animals prior to drug treatment (Figure 2).

Retention. One-factor ANOVAs (with drug treatment as the between-subjects variable) revealed a significant drug effect on the platform location latency measure in the shell $[F(2,32)=4.02, p<.05]$ but not in the core $[F(2,32)=0.36, p>.05]$ animals (Figure $3 \mathrm{~A}$ ). Post hoc tests showed that, in the shell animals, the $100-\mathrm{ng} / \mathrm{side}$ sulpiride group had significantly longer latencies than the saline group $(p<.01)$. In addition, the core-saline group had significantly longer latencies than the shell-saline group $(p<.05)$. On the annulus time measure, one-factor ANOVAs revealed a significant drug effect in the core $[F(2,34)=6.45, p<.005]$ but not in the shell $[F(2,32)=1.68, p>.05]$ animals (Figure 3B). Post hoc tests showed that, in the core animals, both sulpiridetreated groups had significantly lower annulus times than the saline group ( $10 \mathrm{ng} / \mathrm{side}, p<.01 ; 100 \mathrm{ng} / \mathrm{side}, p<$ $.05)$. On the periphery time measure, one-factor ANOVAs revealed a significant drug effect in the core $[F(2,34)=$ $3.65, p<.05]$ but not in the shell $[F(2,34)=1.58, p>$ .05 ] animals (Figure 3C). Post hoc tests showed that, in the core animals, the $10-\mathrm{ng} /$ side sulpiride group spent significantly more time in the maze periphery than did the saline group $(p<.05)$. Finally, on the path length to the platform location measure, one-factor ANOVAs revealed a significant effect of sulpiride in the shell $[F(2,32)=4.74$, $p<.05]$ but not in the core $[F(2,33)=0.08, p>.05]$ animals (Table 1). Post hoc tests showed that, in the shell animals, the 100-ng/side group had significantly longer path lengths to reach the platform location than did the saline group $(p<.01)$.

\section{DISCUSSION}

The results showed that immediate posttraining microinfusions of sulpiride into the NA shell or core impaired different measures of retention in the spatial version of the Morris water maze. Specifically, sulpiride microinfusions into the shell impaired retention only on the platform location latency measure (as well as on the related path length measure), whereas microinfusions into the core impaired retention only on the annulus time and periphery time measures. These findings suggest that both the shell and the core are involved in consolidation of memory for the Morris water maze, but for different aspects of the task.

The performance of shell and core cannulated animals was largely similar during both acquisition and retention following saline microinfusions. There was, however, a significant difference between the platform location latencies in the saline control groups in shell and core animals (see Figure 3A). The cause of this difference is unclear, although it is likely that it is due to differences in the effects of cannula implantation in the shell and core. It should be noted that these differences are probably not attributable to general motor or cognitive impairments in the core animals, however, since there were no significant differences between shell and core saline groups, either in their acquisition latencies or in their annulus or periphery times (and, in fact, the core-saline group performed better than the shell-saline group on the annulus time measure). Regardless of the cause of this difference, it raises the possibility that the high platform location latencies of the saline control group in the core animals may have obscured an impairing effect of sulpiride microinfusions into the core on this measure. However, we believe that this explanation is inadequate for two rea- 

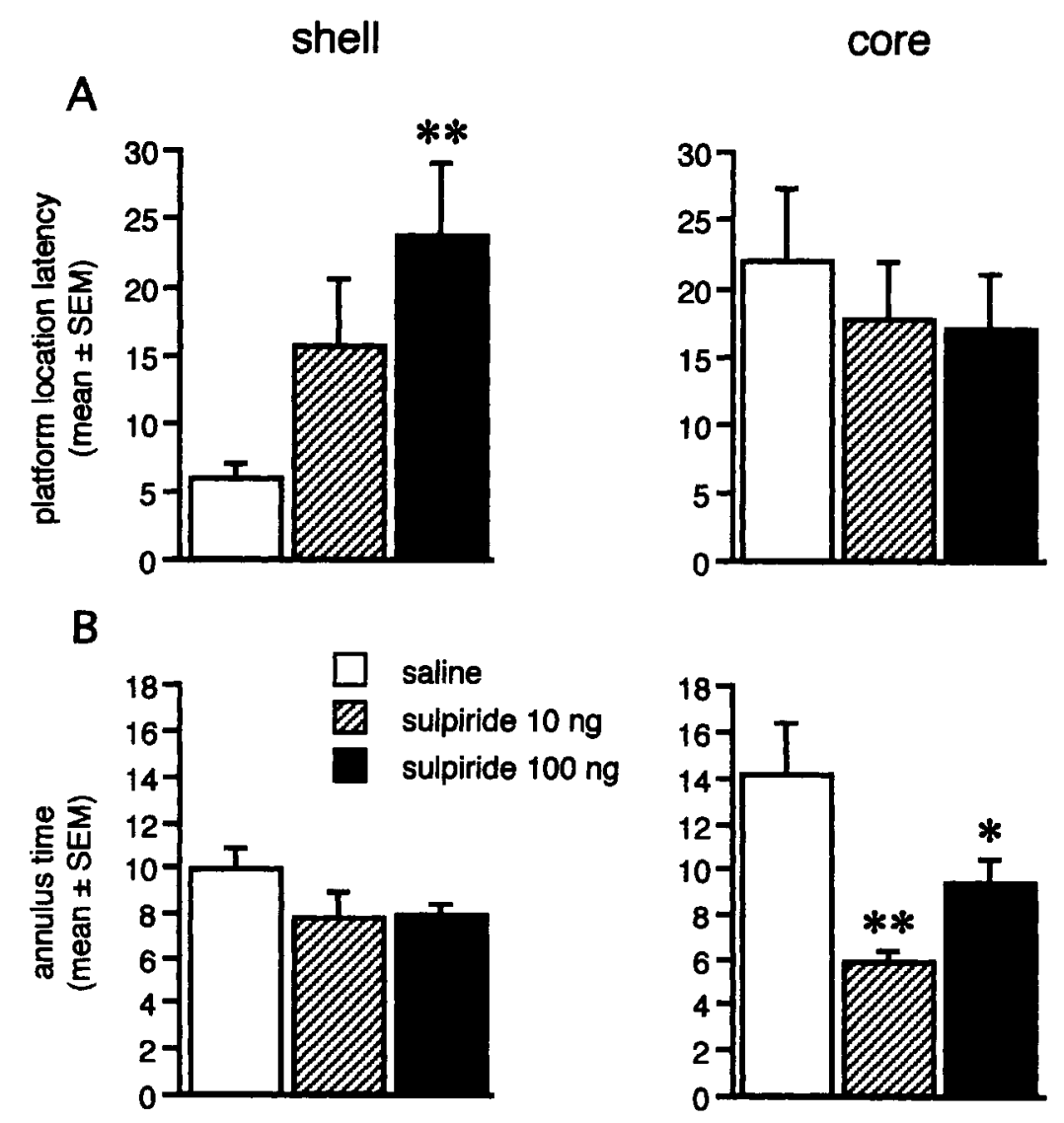

C
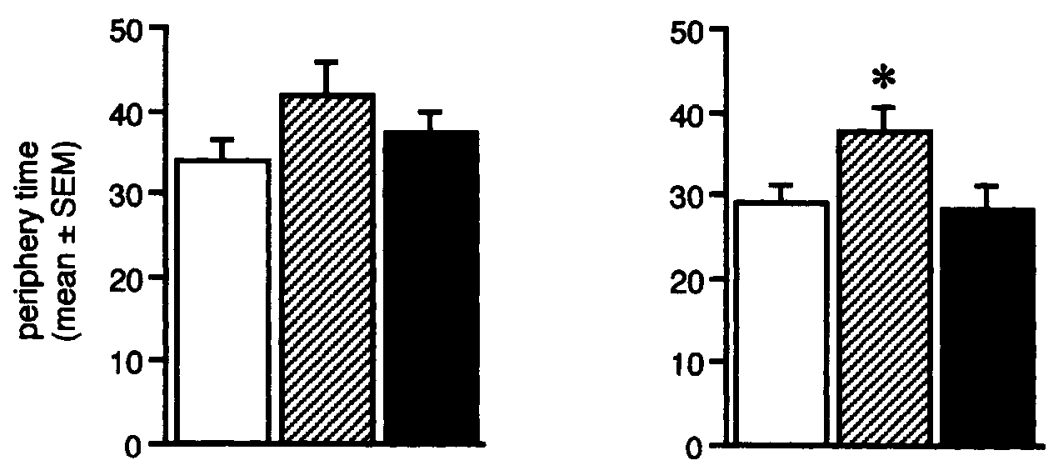

Figure 3. A: mean ( $\pm S E M$ ) latencies to reach the platform location in shell and core animals. B: mean ( $\pm S E M$ ) annulus time in shell and core animals. $C$ : mean ( $\pm S E M$ ) periphery time in shell and core animals (shell, $n=12-13$ animals/group; core, $n=$ 11-14 animals/group). ${ }^{*} p<.05,{ }^{* *} p<.01$, as compared with the corresponding saline control groups.

sons. First, in our previous study employing whole NA microinfusions (Setlow \& McGaugh, 1998), the mean platform location latency of the rats given the most effective dose of sulpiride was $40 \mathrm{sec}$, suggesting that a ceiling effect did not obscure an impairing effect of sulpiride in the core animals in the present study. Second, we have found that, in animals given spatial pretraining in a different water maze prior to training and testing in the water maze used here (and in which the platform location latencies of the saline groups were equivalent in shell and core animals), sulpiride was also only effective in shell animals (Setlow \& McGaugh, unpublished data).

The dissociation suggested here between mnemonic functions of the shell and those of the core is consistent with evidence showing that the two subregions are differentially involved in several behaviors (Maldonado- 
Table 1

Path Length Swum to Platform Location on the Retention Test

\begin{tabular}{llr}
\hline Group & $M$ (in cm) & $\pm 1 S E M$ \\
\hline Shell & & \\
saline & 148.2 & 29.4 \\
$10 \mathrm{ng} / \mathrm{side}$ & 365.8 & 97.2 \\
$100 \mathrm{ng} / \mathrm{side}$ & $652.5^{*}$ & 166.0 \\
Core & & \\
saline & 490.0 & 129.5 \\
$10 \mathrm{ng} / \mathrm{side}$ & 438.0 & 102.1 \\
$100 \mathrm{ng} / \mathrm{side}$ & 507.9 & 128.5 \\
\hline
\end{tabular}

${ }^{*} p<.01$, as compared with shell-saline group.

Irizarry \& Kelley, 1995a, 1995b; Sokolowski \& Salamone, 1998; Weiner et al., 1996). The fact that shell and not core microinfusions impaired platform location latency is inconsistent, however, with the suggestion of Maldonado-Irizarry and Kelley (1995a) that the core is preferentially involved in spatial learning and memory. It also suggests that our initial hypothesis regarding the NA substrate mediating the mnemonic effects of whole-NA sulpiride microinfusions was incorrect, and that in our previous experiment (Setlow \& McGaugh, 1998), the effects of sulpiride on platform location latency were probably mediated by the shell rather than by the core. The similarity in the saline control group latencies in the shell animals in the present study and the whole-NA animals in our previous study (5.6 and $6.8 \mathrm{sec}$, respectively) supports this conclusion.

It should be noted that this conclusion seems not to fit well with evidence that the shell is only weakly innervated by the dorsal hippocampal formation (Groenewegen, Vermeulen-Van der Zee, te Kortschot, \& Witter, 1987), which has been proposed to be the critical part of the hippocampal formation for learning and memory in the Morris water maze (E. Moser, M.-B. Moser, \& Andersen, 1993). Recent findings, however, indicate that the ventral hippocampal formation, which projects strongly to the medial shell (Groenewegen et al., 1987), is also involved in water maze learning (Floresco, Seamans, \& Phillips, 1996). This suggests a potential anatomical substrate for the effects of shell microinfusions on the latency measure (also, see below).

The finding that shell microinfusions of sulpiride impaired retention on the latency measure seems to contradict another finding of Floresco et al. (1996) that pretraining shell microinfusions of lidocaine had no effect on Morris water maze retention, using a measure of path length swum to the platform. This contradiction cannot be explained by the difference in the measures used, as the shell-sulpiride-treated rats in the present experiment were also impaired on the path length measure (Table 1). This finding suggests that the critical difference between the two experiments was that of either the drugs used or the timing of the infusions (pre- vs. posttraining.) An explicit comparison between pre- and posttraining inactivation of the shell should resolve this issue.
Despite the unexpected absence of an effect of core sulpiride microinfusions on the platform location latency measure, it is interesting to note that the pattern of impairments found in the core animals on the three retention measures (impairment on the annulus and periphery time measures, but not on platform location latency) is identical to that produced by sulpiride microinfusions into the posteroventral caudate-putamen (Setlow \& McGaugh, 1999). We previously proposed that this pattern of results represents impaired memory for procedural aspects of water maze performance. For example, an impairment in memory for the strategy "persist in searching away from the wall if you don't find the platform immediately" would produce the pattern of impairments observed in core animals (Setlow \& McGaugh, 1999). It should be pointed out that annulus time (and similar proximity measures, such as quadrant time) is usually thought to measure the same aspect of behavior (memory for the platform location) as does the latency measure, and in many cases (e.g., Markowska, Long, Johnson, \& Olton, 1993), this is probably true. Given that performance on the two measures seems to be dissociable, however, in a manner inconsistent with floor or ceiling effects on either measure (Setlow \& McGaugh, 1999; present study), it seems that the most parsimonious interpretation of these results is that, under the training conditions used here, the annulus and latency measures assess memory for different aspects of task performance.

The finding that the core and caudate-putamen are similarly involved in Morris water maze retention is not surprising in light of the anatomical similarity between these two areas of the striatum (Heimer et al., 1995). Further support for this similarity is found in a recent study in which core microinfusions of an NMDA-receptor antagonist in rats impaired acquisition of an operant barpress task that is also affected by manipulations of the caudate-putamen (Kelley, Smith-Roe, \& Holahan, 1997; Prado-Alcalá, Kaufman, \& Moscona, 1980). Interestingly, the dissociation seen in the present study between the shell and core is similar to that which has been observed between the hippocampus and the caudate-putamen (Packard \& Teather, 1997; Setlow \& McGaugh, 1999).

The proposed differences between the mnemonic functions of the shell and those of the core raise the question of which inputs to these parts of the striatum might mediate these functions. It has been known for some time that different regions of the striatum are often involved in cognitive functions (including learning and memory) in a manner similar to the involvement in these same functions of their cortical afferents (Levy, Friedman, Davachi, \& Goldman-Rakic, 1997; Rolls, 1994; Rosvold, 1972). Application of this principle to the NA suggests that the different mnemonic functions of the shell and core proposed here may be mediated by different sets of cortical afferents. Notably, the involvement in Morris water maze memory of two NA-projecting cortical areas shows some parallels with the involvement of 
the shell and the core in this task. Immediate posttraining microinfusions of AP-5 into the hippocampus impair latency to reach the platform location (Packard \& Teather, 1997). In contrast, immediate posttraining microinfusions of AP-5 into the insular cortex impair retention on a proximity measure (number of platform crossings) similar to the annulus time measure used here, but not on latency to reach the platform location (Gutiérrez, Hernández, Ramírez-Amaya, \& Bermúdez-Rattoni, 1999). It is interesting to speculate that afferents from these two structures may mediate the differential effects of sulpiride in the shell and core, although, clearly, direct comparisons using our measures would be necessary for a more definitive conclusion. Moreover, the potential for emergent mnemonic properties arising from convergence of cortical inputs in the NA must be considered.

The results of this experiment indicate that the NA is involved in consolidation of memory for the water maze. They do not, however, address the question of whether the NA is a site of storage for this memory. NA lesions and intra-NA microinfusions of haloperidol, both of which severely disrupt acquisition in the water maze, have little or no effect on performance in rats that have already acquired the task (Ploeger et al., 1994; Sutherland \& Rodriguez, 1989). These findings suggest that the NA is not a permanent site of storage for water maze memory, or at least that alternative, non-NA-dependent storage sites become available following training. Thus, it is possible that the sulpiride microinfusions in the present study affected memory storage through influences elsewhere in the brain-potentially in cortical areas to which the NA projects through pallido-thalamo-cortical connections (Alexander, Crutcher, \& DeLong, 1990; Groenewegen, Berendse, Wolters, \& Lohman, 1990; Setlow, 1997).

In conclusion, the results of this experiment showed that immediate posttraining microinfusions of sulpiride into the shell and the core subregions of the NA differentially affected several measures of retention in the Morris water maze. Shell microinfusions impaired latency to reach the platform location, but not annulus or periphery time, whereas core microinfusions produced the opposite pattern of results. These results provide evidence for functional differences between the NA shell and core and highlight the importance of differentiating between the two subregions in studies of mnemonic functions of the NA.

\section{REFERENCES}

AleXander, G. E., Crutcher, M. D., \& DeLong, M. R. (1990). Basal ganglia-thalamocortical circuits: Parallel substrates for motor, oculomotor, "prefrontal" and "limbic" functions. Progress in Brain Research, 85, 119-146.

Bannerman, D. M., Good, M. A., Butcher, S. P., Ramsay, M., \& MoRRIS, R. G. M. (1995). Distinct components of spatial learning revealed by prior training and NMDA receptor blockade. Nature, $\mathbf{3 7 8}$, 182-186.
Carlezon, W. A., \& Wise, R. A. (1996). Rewarding actions of phencyclidine and related drugs in nucleus accumbens shell and frontal cortex. Journal of Neuroscience, 16, 3112-3122.

Devan, B. D., Goad, E. H., \& Petri, H. L. (1996). Dissociation of hippocampal and striatal contributions to spatial navigation in the water maze. Neurobiology of Learning \& Memory, 66, 305-323.

Everit, B. J., Morris, K. A., O'Brien, A., \& RobBins, T. W. (1991). The basolateral amygdala-ventral striatal system and conditioned place preference: Further evidence of limbic-striatal interactions underlying reward-related processes. Neuroscience, 42, 1-18.

Floresco, S. B., Seamans, J. K., \& Phillips, A. G. (1996). Differential effects of lidocaine infusions into the ventral CA1/subiculum or the nucleus accumbens on the acquisition and retention of spatial information. Behavioural Brain Research, 81, 163-171.

Floresco, S. B., Seamans, J. K., \& Phillips, A. G. (1997). Selective roles for hippocampal, prefrontal cortical, and ventral striatal circuits in radial-arm maze tasks with or without a delay. Journal of Neuroscience, $17,1880-1890$.

Gal, G., Joel, D., GuSAK, O., Feldon, J., \& Weiner, I. (1997). The effects of electrolytic lesion to the shell subterritory of the nucleus accumbens on delayed non-matching-to-sample and four-arm baited eight-arm radial-maze tasks. Behavioral Neuroscience, 111, 92-103.

Groenewegen, H. J., Berendse, H. W., Wolters, J. G., \& Lohman, A. H. M. (1990). The anatomical relationship of the prefrontal cortex with the striatopallidal system, the thalamus and the amygdala: Evidence for a parallel organization. Progress in Brain Research, 85, 95-118.

Groenewegen, H. J., Vermeulen-Van der Zee, E., te Kortschot, A., \& WitTer, M. P. (1987). Organization of the projections from the subiculum to the ventral striatum in the rat: A study using anterograde transport of Phaseolus vulgaris leucoagglutinin. Neuroscience, 23, 103-120.

Gutiérrez, H., Hernández, E., Ramírez-Amaya, V., \& BermúdeZRatroni, F. (1999). Blockade of NMDA receptors in the insular cortex disrupts taste aversion and spatial memory formation. Neuroscience, 89, 751-758.

Heimer, L., ZahM, D. S., \& Alheid, G. F. (1995). Basal ganglia. In G. Paxinos (Ed.), The rat nervous system (pp. 579-628). San Diego: Academic Press.

Kelley, A. E., Smith-Roe, S. L., \& Holahan, M. R. (1997). Responsereinforcement learning is dependent on $N$-methyl-D-aspartate receptor activation in the nucleus accumbens core. Proceedings of the $\mathrm{Na}$ tional Academy of Sciences, 94, 12174-12179.

Levy, R., Friedman, H. R., Davachi, L., \& Goldman-Rakic, P. S (1997). Differential activation of the caudate nucleus in primates performing spatial and nonspatial working memory tasks. Journal of Neuroscience, 17, 3870-3882.

LoRens, S. A., Sorenson, J. P., \& Harvey, J. A. (1970). Lesions in the nucleus accumbens septi of the rat: Behavioral and neurochemical effects. Journal of Comparative \& Physiological Psychology, 73, 284-290.

Lorenzini, C. A., Baldi, E., Bucharelli, C., \& TAssoni, G. (1995). Time-dependent deficits of rat's memory consolidation induced by tetrodotoxin injections into the caudate-putamen, nucleus accumbens, and globus pallidus. Neurobiology of Learning \& Memory, 63, 87-93.

Maldonado-Irizarry, C. S., \& Kelley, A. E. (1995a). Excitatory amino acid receptors with nucleus accumbens subregions differentially mediate spatial learning in the rat. Behavioural Pharmacology, 6, 527-539.

Maldonado-IrizarRY, C. S., \& Kelley, A. E. (1995b). Excitotoxic lesions of the core and shell subregions of the nucleus accumbens differentially disrupt body weight regulation and motor activity in rat. Brain Research Bulletin, 38, 551-559.

Markowska, A. L., Long, J. M., Johnson, C. T., \& Olton, D. S. (1993). Variable-interval probe test as a tool for repeated measurements of spatial memory in the water maze. Behavioral Neuroscience, 107, 627-632.

McCullough, L. D., Sokolowski, J. D., \& Salamone, J. D. (1993). 
A neurochemical and behavioral investigation of the involvement of nucleus accumbens dopamine in instrumental avoidance. Neuroscience, 52, 919-925.

McGeorge, A. J., \& FAull, R. L. M. (1989). The organization of the projection from the cerebral cortex to the striatum in the rat. Neuroscience, 29, 503-537.

Moser, E., Moser, M.-B., \& ANDERSEN, P. (1993). Spatial learning impairment parallels the magnitude of dorsal hippocampal lesions, but is hardly present following ventral lesions. Journal of Neuroscience, 13, 3916-3925.

Packard, M. G., Cahill, L., \& McGaugh, J. L. (1994). Amygdala modulation of hippocampal-dependent and caudate nucleus-dependent memory processes. Proceedings of the National Academy of Sciences, 91, 8477-8481.

PaCkard, M. G., \& TEather, L. A. (1997). Double dissociation of hippocampal and dorsal striatal memory systems by posttraining intracerebral injections of 2-amino-5-phosphonopentanoic acid. Behavioral Neuroscience, 111, 543-551.

Packard, M. G., \& WhITE, N. M. (1991). Dissociation of hippocampus and caudate nucleus memory systems by posttraining intracerebral injection of dopamine agonists. Behavioral Neuroscience, 105, 295 306.

Parkinson, J. A., Willoughby, P. W., Robbins, T. W., \& Everitt, B. J. (1997). Cortico-striatal circuitry: Evidence for a functional connection between anterior cingulate cortex and nucleus accumbens core in Pavlovian conditioning. Society for Neuroscience Abstracts, 23, 779.

Paxinos, G., \& Watson, C. (1997). The rat brain in stereotaxic coordinates (3rd ed.). San Diego: Academic Press.

Ploeger, G. E., Spruijt, B. M., \& CoOls, A. R. (1994). Spatial localization in the Morris water maze in rats: Acquisition is affected by intra-accumbens injections of the dopaminergic antagonist haloperidol. Behavioral Neuroscience, 108, 927-934.

Prado-Alcalá, R. A., Kaufman, P., \& Moscona, R. (1980). Scopolamine and $\mathrm{KCl}$ injections into the caudate nucleus: Overtraininginduced protection against deficits of learning. Pharmacology, Biochemistry \& Behavior, 12, 249-253.

RolLs, E. T. (1994). Neurophysiology and cognitive functions of the striatum. Revue Neurologique, 150, 648-660.

RosvoLD, H. E. (1972). The frontal lobe system: Cortical-subcortical interrelationships. Acta Neurobiologiae Experimentalis, 32, 439-460.
Seamans, J. K., \& Phillips, A. G. (1994). Selective memory impairments produced by transient lidocaine-induced lesions of the nucleus accumbens in rats. Behavioral Neuroscience, 108, 456-468.

SetLow, B. (1997). The nucleus accumbens and learning and memory. Journal of Neuroscience Research, 49, 515-521.

SetLow, B., \& MCGaugh, J. L. (1998). Sulpiride infused into the nucleus accumbens post-training impairs retention in the spatial water maze. Behavioral Neuroscience, 112, 603-610.

Setlow, B., \& McGaugh, J. L. (1999). Involvement of the posteroventral caudate-putamen in memory consolidation in the Morris water maze. Neurobiology of Learning \& Memory, 71, 240-247.

Sokolowski, J. D., \& SALAmONE, J. D. (1998). The role of accumbens dopamine in lever pressing and response allocation: Effects of 6OHDA injected into the core and dorsomedial shell. Pharmacology Biochemistry \& Behavior, 59, 557-566.

SQuire, L. R., \& KNOWLTON, B. J. (1994). Memory, hippocampus and brain systems. In M. Gazzaniga (Ed.), The cognitive neurosciences (pp. 825-837). Cambridge, MA: MIT Press.

Stern, C. E., \& Passingham, R. E. (1995). The nucleus accumbens in monkeys (Macaca fascicularis): III. Reversal learning. Experimental Brain Research, 106, 239-247.

Sutherland, R. J., \& Rodriguez, A. J. (1989). The role of the fornix/fimbria and some related subcortical structures in place learning and memory. Behavioural Brain Research, 32, 265-277.

Taghzouti, K., Garrigues, A. M., Labouesse, J., Le Moal, M., \& SimON, H. (1987). Bovine serum albumin-haloperidol as a tool for the study of dopaminergic transmission: Behavioral and neurochemical effects following a single injection in the nucleus accumbens. Life Sciences, 40, 127-137.

Weiner, I., Gal, G., RaWlins, J. N. P., \& Feldon, J. (1996). Differential involvement of the shell and core subterritories of the nucleus accumbens in latent inhibition and amphetamine-induced activity. $B e$ havioural Brain Research, 81, 123-133.

Westbrook, R. F., Goon, A. J., \& Kiernan, M. J. (1997). Microinjection of morphine into the nucleus accumbens impairs contextual learning in rats. Behavioral Neuroscience, 111, 996-1013.

(Manuscript received August 4, 1998; revision accepted for publication November 23, 1998.) 